\title{
Hydroxyl carboxylate based non-phosphorus corrosion inhibition process for reclaimed water pipeline and downstream recirculating cooling water system
}

\author{
Jun Wang ${ }^{1,2, *}$, Dong Wang ${ }^{1,3}$, Deyin Hou $^{1,2}$ \\ 1. Key Laboratory of Drinking Water Science and Technology, Research Center for Eco-Environmental Sciences, Chinese Academy of Sciences, \\ Beijing 100085, China \\ 2. Beijing Key Laboratory of Industrial Wastewater Treatment and Reuse, Research Center for Eco-Environmental Sciences, Chinese Academy of \\ Sciences, Beijing 100085, China \\ 3. Yanshan Branch, SINOPEC Beijing Research Institute of Chemical Industry, Beijing 102500, China
}

\section{A R T I C L E I N F O}

Article history:

Received 23 July 2015

Revised 6 October 2015

Accepted 7 October 2015

Available online 8 December 2015

Keywords:

Hydroxyl carboxylate

Reclaimed water

Pipeline

Corrosion

Recirculating cooling water system

Non-phosphorus

\begin{abstract}
A B S T R A C T
A combined process was developed to inhibit the corrosion both in the pipeline of reclaimed water supplies (PRWS) and in downstream recirculating cooling water systems (RCWS) using the reclaimed water as makeup. Hydroxyl carboxylate-based corrosion inhibitors (e.g., gluconate, citrate, tartrate) and zinc sulfate heptahydrate, which provided $\mathrm{Zn}^{2+}$ as a synergistic corrosion inhibition additive, were added prior to the PRWS when the phosphate (which could be utilized as a corrosion inhibitor) content in the reclaimed water was below $1.7 \mathrm{mg} / \mathrm{L}$, and no additional corrosion inhibitors were required for the downstream RCWS. Satisfactory corrosion inhibition was achieved even if the RCWS was operated under the condition of high numbers of concentration cycles. The corrosion inhibition requirement was also met by the appropriate combination of $\mathrm{PO}_{4}^{3-}$ and $\mathrm{Zn}^{2+}$ when the phosphate content in the reclaimed water was more than $1.7 \mathrm{mg} / \mathrm{L}$. The process integrated not only water reclamation and reuse, and the operation of a highly concentrated RCWS, but also the comprehensive utilization of phosphate in reclaimed water and the application of non-phosphorus corrosion inhibitors. The proposed process reduced the operating cost of the PRWS and the RCWS, and lowered the environmental hazard caused by the excessive discharge of phosphate. Furthermore, larger amounts of water resources could be conserved as a result.
\end{abstract}

(c) 2015 The Research Center for Eco-Environmental Sciences, Chinese Academy of Sciences. Published by Elsevier B.V.

\section{Introduction}

The corrosion of water pipelines, occurring either in drinking water distribution systems or in wastewater collection facilities, has been a major concern (Edwards, 2004; Romer and Passaro, 2007). Without appropriate maintenance, pipelines, especially those made of metals, will be quickly attacked and eroded by dissolved gases, ions and organic matters. As a result, pipeline leakage can cause water loss and contamination, ambient pollution, and high cost for not only pipeline restoration, but also the remediation of water and the surrounding environment.

In recent years, wastewater reuse has gained great attention in regions that suffer from water scarcity, and a

\footnotetext{
*Corresponding author: E-mail: junwang@rcees.ac.cn (Jun Wang).
} 
number of facilities for advanced treatment and reclaiming of wastewater were constructed (Yi et al., 2011). The reclaimed water contains more contaminants and has more severe corrosivity than fresh water. Therefore, designs for appropriately inhibiting the corrosion in the pipelines of reclaimed water supplies (PRWS) are necessary (Kim et al., 2012). Unfortunately, the corrosion issues of the PRWS were largely neglected in the past and have only been seriously considered recently.

Typical techniques for pipeline corrosion control include material selection, protective coatings and linings, cathodic protection and dosing with corrosion inhibitors (Ellenberger, 2014; Buchheit, 2005; Sastri, 2011). Among the four techniques, the former three are usually applied in the construction of new pipelines, whereas only the last technique can be utilized with existing pipelines. As such, the main objective of the present study is to develop a process for satisfactory corrosion inhibition in the existing PRWS by dosing with inhibitors.

Reclaimed water is often reused as municipal and domestic non-potable water or makeup water for industrial cooling circuits (Safari et al., 2013; Choudhury et al., 2012). Coincidently, the corrosion issue is also the main concern for industrial cooling water systems, which requires the use of corrosion inhibitors as well. As such, a corrosion inhibition formula for both PRWS and downstream recirculating cooling water systems (RCWS) by dosing with the same inhibitors can be envisaged. The realization of such a system not only simultaneously solves the corrosion issue for both systems, but also streamlines the overall operation.

Reclaimed waters usually contain trace amounts of phosphorus compounds, such as orthophosphate, polyphosphate, and organic phosphates, which cannot be completely removed from raw wastewaters by either secondary or advanced treatments. On the one hand, as it is known as an effective corrosion inhibitor (Frayne, 1999), the presence of phosphate in reclaimed waters could potentially assist the corrosion inhibition in PRWS and RCWS, thus lowering the consumption of additional corrosion inhibitors. On the other hand, phosphorus is one of the essential nutrients for organisms, and its excess emission could lead to eutrophication of environmental waters. So, in recent years, the content of phosphorus in water or the application of phosphorus chemicals has been strictly monitored and controlled by environmental regulations. Therefore, the use of phosphate as corrosion inhibitor and especially its dosage should be carefully examined. The addition of other novel non-phosphorus corrosion inhibitors such as gluconates (one type of hydroxyl carboxylate) (Touir et al., 2008, 2014; Belakhmima et al., 2015; Manjula, 2009) to complement phosphorus corrosion inhibitors offers an alternative approach to better utilize phosphate present in water while minimizing its negative impacts. Furthermore, the use of hydroxyl carboxylates, including citrates and tartrates, as corrosion inhibitors has been investigated in previous studies on the corrosion inhibitions of aluminum and zinc (Müller, 2004; Shao et al., 2002; Renuka et al., 1998). Hence their corrosion inhibition functionality on mild steel can be expected.

The objective of this study is therefore to develop an environmentally friendly and economically viable process to prevent the corrosion taking place in both PRWS and downstream RCWS, by dosing hydroxyl carboxylates, phosphates and other corrosion inhibition additives in the water source.

\section{Materials and methods}

\subsection{Characterization of the reclaimed water}

The reclaimed water (raw water), a secondary-treated municipal wastewater effluent (i.e., Orbal oxidation ditch followed by secondary clarification), was collected from Fangshan Chengguan Wastewater Treatment Plant in Beijing, China. Its characteristics were determined by using appropriate standard test procedures (China EPA, 2002) and the results are presented in Table 1. Fresh water was collected from SINOPEC Beijing Yanshan Company in Beijing, China, and used for the purpose of comparing its corrosivity in pipelines with the reclaimed water, whose characteristics are also provided in Table 1. The most noticeable differences between the reclaimed water in PRWS and RCWS include the water temperature, total dissolved solid (TSS) content and organic contaminant content. To reflect the condition of the highly concentrated RCWS in bench experiments, simulated cooling water was prepared by adding certain amounts of soluble salts to the reclaimed water. In this work, anhydrous calcium

Table 1 - The characteristics comparison of secondary-treated municipal wastewater and fresh water.

\begin{tabular}{|c|c|c|c|}
\hline Parameters & Reclaimed water & Fresh water & Simulated cooling water \\
\hline $\mathrm{Ca}^{2+}(\mathrm{mg} / \mathrm{L})^{\mathrm{a}}$ & 275.4 & 158.7 & 1512 \\
\hline Total hardness $(\mathrm{mg} / \mathrm{L})^{\text {a }}$ & 398.6 & 198.3 & 1645 \\
\hline Total alkalinity $(\mathrm{mg} / \mathrm{L})^{a}$ & 227.5 & 145.8 & 188.3 \\
\hline $\mathrm{Cl}^{-}(\mathrm{mg} / \mathrm{L})$ & 191.1 & 32.3 & 1065 \\
\hline $\mathrm{SO}_{4}^{2-}(\mathrm{mg} / \mathrm{L})$ & 233.2 & 45.5 & 1306 \\
\hline Total iron $(\mathrm{mg} / \mathrm{L})$ & 0.08 & 0.03 & 0.10 \\
\hline Total phosphorus $(\mathrm{mg} / \mathrm{L})^{\mathrm{b}}$ & 1.42 & N.D. & 1.43 \\
\hline Orthophosphate $(\mathrm{mg} / \mathrm{L})^{\mathrm{b}}$ & 1.40 & N.D. & 1.37 \\
\hline Conductivity $(\mu \mathrm{S} / \mathrm{cm})$ & 1098 & 627 & 4325 \\
\hline $\mathrm{pH}$ & 7.73 & 7.65 & 7.35 \\
\hline Turbidity (NTU) & 3.25 & N.D. & 4.33 \\
\hline $\mathrm{COD}_{\mathrm{Cr}}(\mathrm{mg} / \mathrm{L})$ & 20 & N.D. & 21 \\
\hline
\end{tabular}


chloride was added to increase the $\mathrm{Ca}^{2+}$ concentration in the reclaimed water up to $1500 \mathrm{mg} / \mathrm{L}$, and anhydrous sodium sulfate was added to balance the anions (e.g., $\mathrm{Cl}^{-}, \mathrm{SO}_{4}^{2-}$ ) in the water, which were expected to have significant impact on the corrosion of carbon steel. The characteristics of the simulated cooling water are listed in Table 1 . Some parameters of the simulated cooling water, such as total iron content, total phosphorus content and dichromate chemical oxygen demand $\left(C_{C D}\right)$ concentration, were slightly different from the actual cooling water, but still within the acceptable level, and therefore considered suitable for the preliminary evaluation of corrosion inhibition using the proposed chemical formula.

\subsection{Chemicals}

Three hydroxyl carboxylates, sodium gluconate (SG) (>99\%), sodium citrate (SC) (>99\%) and sodium tartrate (ST) (>99\%), were all purchased from Sinopharm Chemical Reagent Co. Ltd. (Shanghai, China) and used as non-phosphorus corrosion inhibitors. A synergistic corrosion inhibitor, Zinc sulfate heptahydrate (>99\%), was also purchased from Sinopharm Chemical Reagent Co. Ltd. An antiscalant, Polyepoxysuccinic acid (PESA) with an active matter content of above $50 \%$ (wt.), was acquired from Changzhou Jingke Xiafeng Fine Chemical Co. Ltd. (Jiangsu, China). A water soluble acrylic acid/2-acrylamide-2methylpropanesulfonic acid copolymer with a solid matter content of above $30 \%$ (wt.) under the trademark of LN-104B was purchased from Changzhou Global Chemicals Co. Ltd. (Jiangsu, China) and used as the dispersant. In addition, sodium dichloroisocyanurate was used as the biocide in the pilot-scale experiment for biofouling control.

\subsection{Bench experiment}

The corrosion inhibition performance of the chemical formulations in PRWS and RCWS was tested using the Rotation Specimen
Method (China Association for Chemical Standardization, 2000). The experimental procedure was as follows: (1) The clean steel coupons $\left(20^{\#}\right.$ mild steel, a kind of mild and low-carbon steel containing approximately $0.2 \%$ carbon) were weighed and fixed on a RCC-II rotating coupon corrosion tester (Jiangsu Gaoyou Instrument Factory, China); (2) the coupons were dipped into experimental solutions containing corrosion and scale inhibitors and dispersants; (3) the experiments were performed at a constant temperature $(\mathrm{T})$ with a predetermined rotating speed (RS) for $72 \mathrm{hr}$; and (4) the coupons were then washed by hydrochloric acid solution (10 wt.\%) and weighed again to obtain the corrosion rate using Eq. (1) below:

Corrosion rate $=\frac{87,600 \times \Delta \mathrm{W}}{\mathrm{S} \times \rho \times \mathrm{t}}$

where, corrosion rate (mm/year) can be expressed as the "speed" at which the corrosion process takes place and how fast the metal is consumed by corrosion, $\Delta \mathrm{W}(\mathrm{g})$ is the weight loss of the coupon, $S\left(\mathrm{~cm}^{2}\right)$ is the superficial area of the coupon, $\rho\left(g / \mathrm{cm}^{3}\right)$ is the density of the coupon, and $t(\mathrm{hr})$ is the experimental time.

\subsection{Pilot-scale recirculating cooling water system experiment}

A pilot-scale RCWS designed and installed in-house was used to evaluate the performance of the cooling water chemical formula (Manufacturing and Developing Department of SINOPEC, 1993; Chien et al., 2012), and its process is shown in Fig. 1.

The cooling water was first pumped from the cooling tower basin to the test tube $\left(20^{\#}\right.$ carbon steel, $\varnothing 10 \times 1 \times 500 \mathrm{~mm}$, chromium plated outside) which was located in the heat exchanger, while the flow rate was controlled at $180 \mathrm{~L} / \mathrm{min}$ by a rotameter. Then the cooling water was heated in the heat exchanger and the inlet and outlet temperatures of the tube were maintained at $32.0 \pm 1.0^{\circ} \mathrm{C}$ and $42.0 \pm 1.0^{\circ} \mathrm{C}$ respectively. Next, the heated water was introduced to the cooling tower

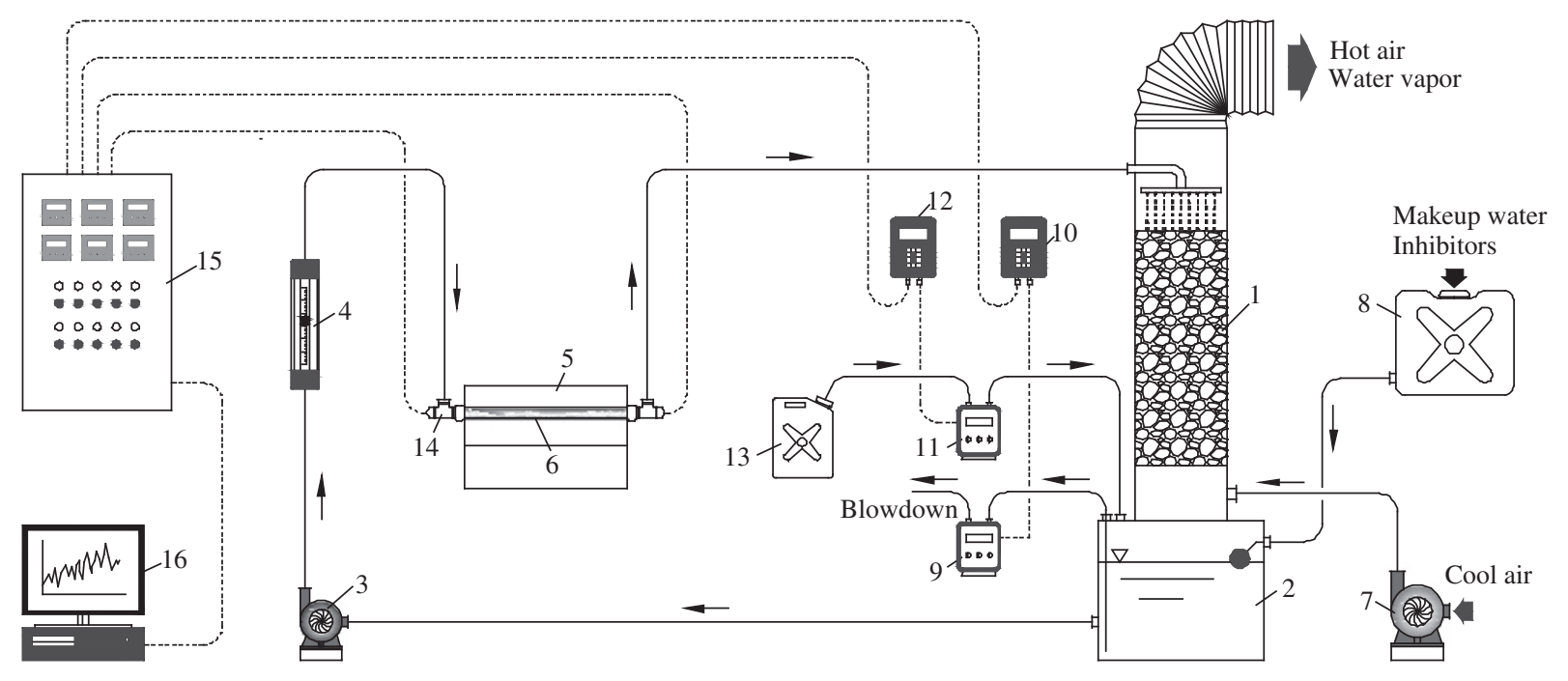

Fig. 1 - Schematic representation of the pilot-scale recirculating cooling water systems (RCWS). (1) Cooling tower; (2) cooling tower basin; (3) circulating pump; (4) rotameter; (5) heat exchanger; (6) test tube; (7) root's blower; (8) makeup water tank; (9) blowdown pump; (10) conductivity controller; (11) acid-dosing pump; (12) pH-controller; (13) sulfuric acid tank; (14) temperature probe; (15) control cabinet; (16) computer. 
for cooling. Finally, the cooled water went down into the basin and finished the cycle.

The reclaimed water treated by lime to remove phosphates was used as the makeup water for the system. The water volume in the system was maintained by adding makeup water to the basin through the ball float valve. The corrosion and scale inhibitors were supplied along with the makeup water. If the amount of inhibitors became lower than the predetermined values, extra dosage of the inhibitors could be added to the basin directly. Moreover, $30 \mathrm{mg} / \mathrm{L}$ of sodium dichloroisocyanurate was added to the basin on a daily basis to minimize any potential biofouling. The cooling water could be automatically discharged from the basin when the $\mathrm{Ca}^{2+}$ concentration exceeded $1500 \mathrm{mg} / \mathrm{L}$. Sulfuric acid was added by an automatic $\mathrm{pH}$-controller during the test to manage the $\mathrm{pH}$ of the cooling water in the desired range. The duration of the test was 20 days, and the adhesion rate and the corrosion rate of the test tubes were obtained by the weight gain and the weight loss of the tubes. The adhesion rate $\left(\mathrm{mg} /\left(\mathrm{cm}^{2} \cdot \mathrm{month}\right)\right)$ is represented by a weight of total deposit on the inside surface of a test tube in a period of time and was calculated using the Eq. (2) below:

Adhesion rate $=\frac{720,000 \times\left(\mathrm{W}_{1}-\mathrm{W}_{2}\right)}{\mathrm{S} \times \mathrm{t}}$

where $W_{1}(g)$ is the weight of the test tube without cleansing by acid after the experiment, $W_{2}(g)$ is the weight of the acid-washed test tube after the experiment, $S\left(\mathrm{~cm}^{2}\right)$ is the inner superficial area of the test tube, and $t(\mathrm{hr})$ is the experimental time. During the same period, some coupons of $20^{\#}$ carbon steel were suspended in the cooling tower basin for comparison purposes.

\section{Results and discussion}

\subsection{Corrosion inhibition study on PRWS}

\subsubsection{Corrosion inhibition requirement}

The Ryznar Saturation Index (RSI), an estimated parameter of the corrosion potential in water based on $\mathrm{Ca}^{2+}$ concentration, alkalinity and saturated $\mathrm{pH}$, was calculated from the data in Table 1 (Frayne, 1999). The RSIs of the reclaimed water and the fresh water were 6.88 and 7.59 respectively, suggesting that the mild steel is more prone to corrode in fresh water than in reclaimed water. In the present study, the corrosion rates at different temperatures in the reclaimed water were tested, and compared against that in the fresh water at the corresponding temperatures. As shown in Fig. 2, the corrosion rate in the reclaimed water was much higher than that in the fresh water, which was opposite to the trends observed in RSI, indicating that some characteristics of the reclaimed water, such as $\mathrm{Cl}^{-}, \mathrm{SO}_{4}^{2-}$ and organic pollutants, might have great impact on the corrosion of the mild steel. The corrosion rate drastically increased when the temperatures increased from 15 to $25^{\circ} \mathrm{C}$, followed by a much more moderate increase at the temperatures of $30-35^{\circ} \mathrm{C}$, probably due to the competition between the corrosion driven by the difference of dissolved oxygen concentration (DO) and the inhibition achieved by the formation of a 'protective film', once rusted, which would also slow down the corrosion to a certain extent. The maximum

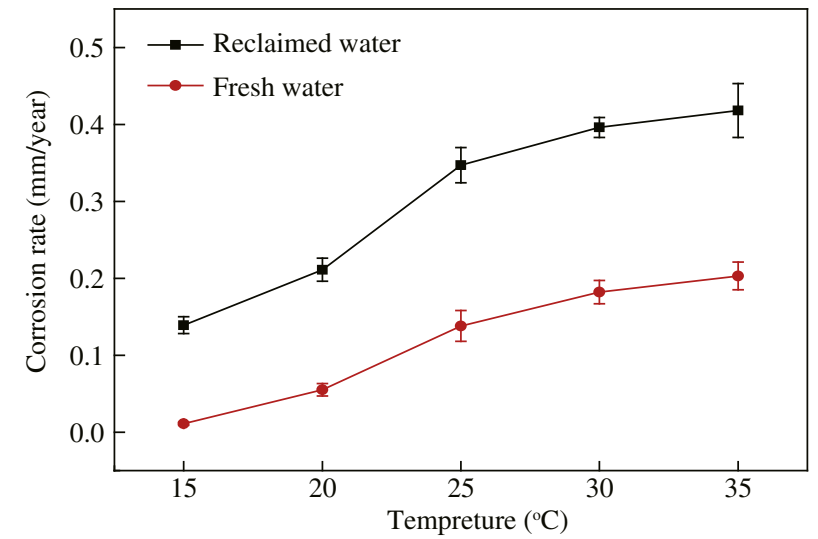

Fig. 2 - The corrosion rate of mild steel at different temperatures in the reclaimed water and in the fresh water. Experimental condition: rotating speed (RS) $=120 \mathrm{r} / \mathrm{min}$.

corrosion rate in the fresh water was observed to be $0.2 \mathrm{~mm} /$ year within the range of temperatures assessed, which could be used as an evaluation index (satisfactory corrosion inhibition) of the corrosion inhibition in the reclaimed water.

\subsubsection{Corrosion inhibition of phosphate}

Orthophosphate $\left(\mathrm{PO}_{4}^{3-}\right)$ has been used as an effective anodic corrosion inhibitor in water treatment (Frayne, 1999). However, as demonstrated in the previous section, the $\mathrm{PO}_{4}^{3-}$ concentration of $1.4 \mathrm{mg} / \mathrm{L}$ was not sufficient to prevent corrosion in the reclaimed water. In this regard, an experiment was conducted to access the effect of dosing extra phosphate on the corrosion rate of mild steel. Fig. 3 shows that the corrosion rate of mild steel dropped linearly from $0.405 \mathrm{~mm} /$ year at the $\mathrm{PO}_{4}^{3-}$ concentration of $1.4 \mathrm{mg} / \mathrm{L}$ to $0.203 \mathrm{~mm} /$ year at the $\mathrm{PO}_{4}^{3-}$ concentration of $3.0 \mathrm{mg} / \mathrm{L}$, which was close to the requirement ( $<0.2 \mathrm{~mm} /$ year), suggesting that the corrosion could be inhibited by dosing with phosphate alone. However, the dosage of phosphate was strictly limited since the $\mathrm{PO}_{4}^{3-}$ concentration needs to be below $3.0 \mathrm{mg} / \mathrm{L}$

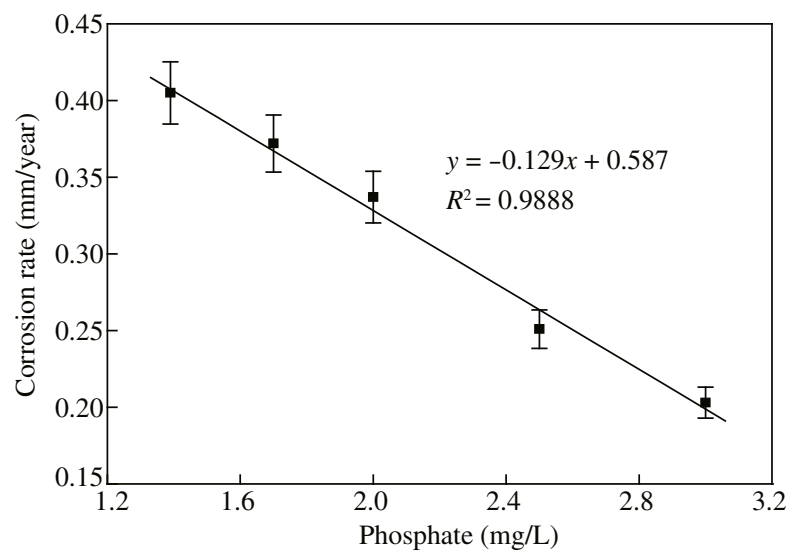

Fig. 3 - The effect of dosing phosphate on the corrosion rate of mild steel in the reclaimed water. Experimental condition: $\mathrm{RS}=120 \mathrm{r} / \mathrm{min}$; temperature $=30^{\circ} \mathrm{C}$. 


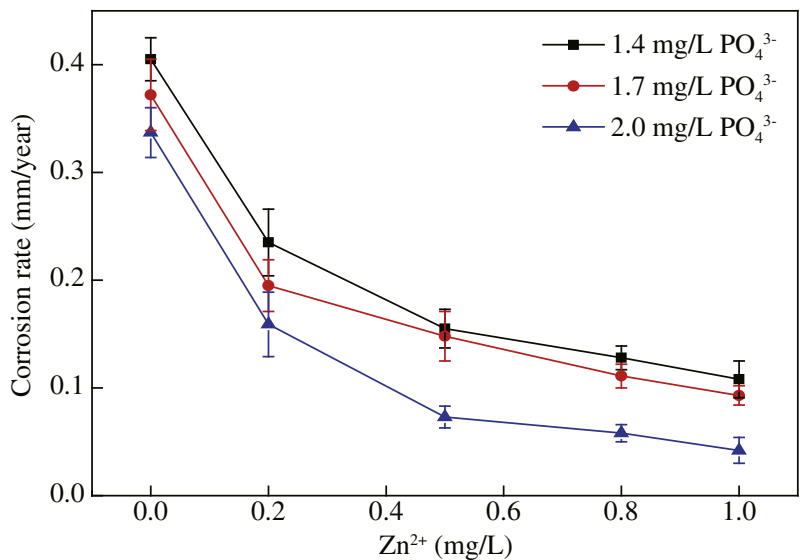

Fig. 4 - The corrosion inhibition improved by the combination of $\mathrm{PO}_{4}^{3-}$ and $\mathrm{Zn}^{2+}$ in the reclaimed water. Experimental condition: $\mathrm{RS}=120 \mathrm{r} / \mathrm{min}$; temperature $=30^{\circ} \mathrm{C}$.

according to water quality standards for reclaimed water (China Ministry of Housing and Urban-Rural Development, 2005). In view of this concern, the use of additional inhibitors was necessary to meet the requirement.

\subsubsection{Synergistic corrosion inhibition of zinc sulfate}

Inorganic zinc salts $\left(\mathrm{Zn}^{2+}\right)$ are commonly used as a corrosion inhibition additive in water treatment, and the combination of $\mathrm{PO}_{4}^{3-}$ and $\mathrm{Zn}^{2+}$ could synergistically enhance the corrosion inhibition effect by quickly forming a sedimentary film on the metal surface (Razi, 1989). Zinc sulfate heptahydrate therefore was used in this study to enhance the corrosion inhibition of the mild steel in the reclaimed water, while extra phosphate was still dosed. As shown in Fig. 4, the combination of $\mathrm{PO}_{4}^{3-}$ and $\mathrm{Zn}^{2+}$ significantly improved the corrosion inhibition, and the corrosion rate decreased with the increase of the $\mathrm{Zn}^{2+}$ and the $\mathrm{PO}_{4}^{3-}$ concentrations. Good corrosion inhibition was achieved with the $\mathrm{Zn}^{2+}$ concentration at $0.5 \mathrm{mg} / \mathrm{L}$ without dosing extra phosphate, revealing an excellent supplemental effect from $\mathrm{Zn}^{2+}$. In addition, similar corrosion inhibition was also observed with the $\mathrm{Zn}^{2+}$ concentration at only $0.2 \mathrm{mg} / \mathrm{L}$ when $0.3 \mathrm{mg} / \mathrm{L}$ extra phosphate was dosed. With the $\mathrm{PO}_{4}^{3-}$ concentration increased to $2.0 \mathrm{mg} / \mathrm{L}$, a better corrosion rate of below $0.1 \mathrm{~mm} / \mathrm{y}$ was obtained with a $\mathrm{Zn}^{2+}$ concentration up to $0.5 \mathrm{mg} / \mathrm{L}$, suggesting that the corrosion inhibition could be enhanced by dosing with more phosphate and zinc sulfate. However, considering the environmental risks caused by phosphorus-related products, a non-phosphorus corrosion inhibition formula should be considered.

2.1.4. Complementary corrosion inhibition of hydroxyl carboxylates Three hydroxyl carboxylates, SG, SC and ST, were studied in bench experiments to evaluate their corrosion inhibition functionality under the conditions of PRWS. Fig. 5a shows the corrosion inhibition of hydroxyl carboxylates at an initial $\mathrm{PO}_{4}^{3-}$ concentration of $1.4 \mathrm{mg} / \mathrm{L}$. The results indicated that the corrosion rates significantly declined when the dosage of hydroxyl carboxylates was increased, and the corrosion inhibition followed the order of ST, SG and SC. $\mathrm{Zn}^{2+}$ showed a positive effect on the corrosion inhibition. Corrosion inhibition below $0.2 \mathrm{~mm} /$ year was achieved with a dosage of hydroxyl carboxylates of only $0.5 \mathrm{mg} / \mathrm{L}$ and $\mathrm{Zn}^{2+}$ concentration of $0.2 \mathrm{mg} / \mathrm{L}$, suggesting that the combination of hydroxyl carboxylates, $\mathrm{PO}_{4}^{3-}$ and $\mathrm{Zn}^{2+}$ had excellent corrosion inhibition performance for mild steel. However, since the phosphate content of the reclaimed water changed over time, the corrosion risk of the reclaimed water with very low phosphate concentration should also be of concern. As such, an experiment in the absence of phosphate was performed, and the phosphate was completely removed from the reclaimed water by precipitation with lime.

The same relationship between the corrosion rate and the dosage of corrosion inhibitors was found, as shown in Fig. $5 b$. However, for different hydroxyl carboxylates, varying amounts of hydroxyl carboxylates and $\mathrm{Zn}^{2+}$ were required to meet the corrosion inhibition requirement of $0.2 \mathrm{~mm} / \mathrm{y}$. In terms of SG
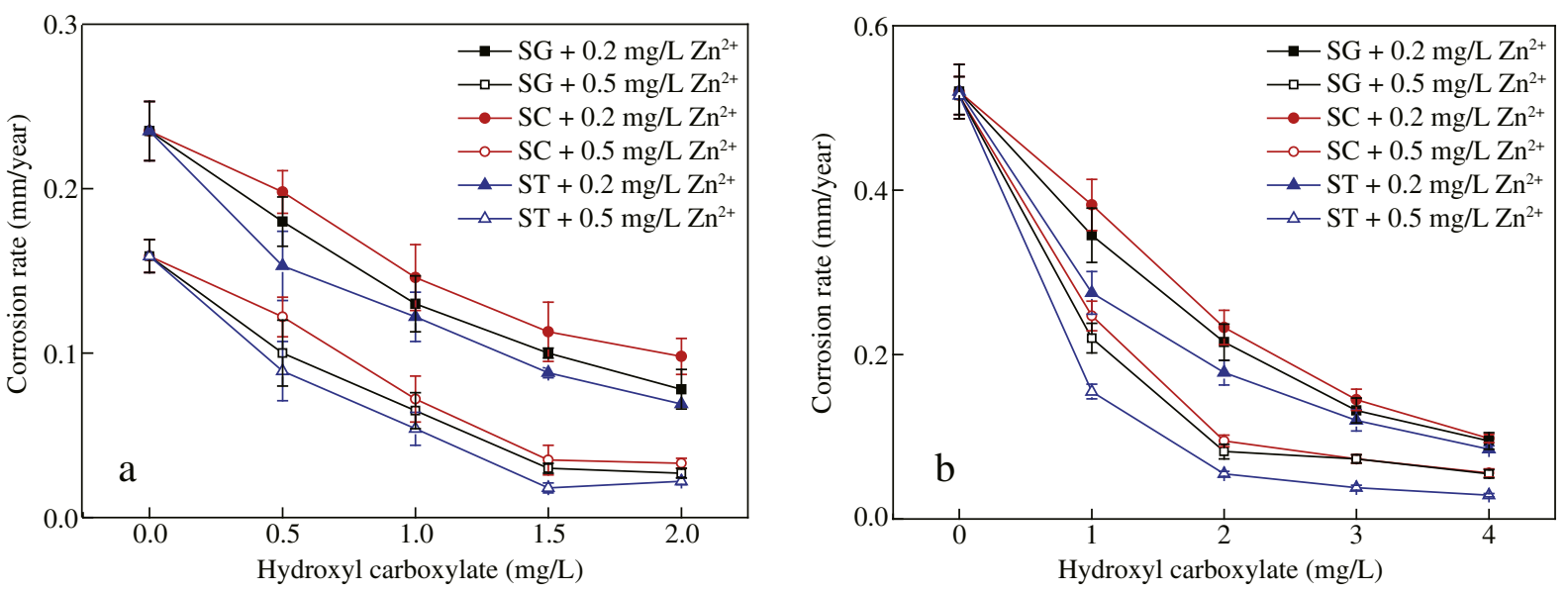

Fig. 5 - The effect of dosing hydroxyl carboxylates on the corrosion rate of mild steel in the reclaimed water. (a) In the presence of phosphate at $1.4 \mathrm{mg} / \mathrm{L}$; (b) in the absence of phosphate. Experimental condition: $\mathrm{RS}=120 \mathrm{r} / \mathrm{min}$; temperature $=30^{\circ} \mathrm{C}$. $\mathrm{SG}$ : sodium gluconate, SC: sodium citrate, ST: sodium tartrate. 
<smiles>COC(=O)C(O)C(O)C(O)C(O)CO</smiles>

SG

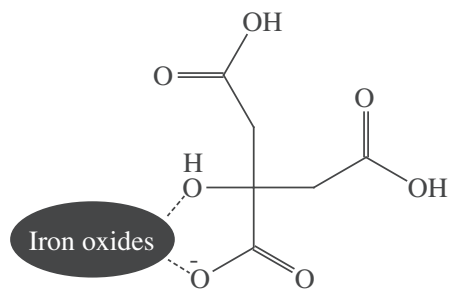

$\mathrm{SC}$

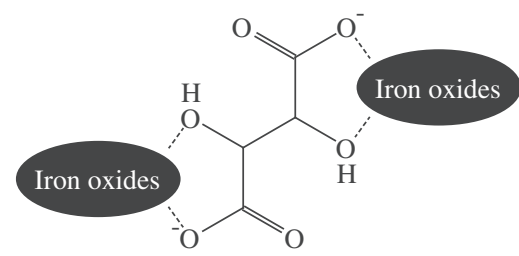

ST

Fig. 6 - The corrosion inhibition mechanism of hydroxyl carboxylates.

and SC, dosages of $3 \mathrm{mg} / \mathrm{L}$ and $2 \mathrm{mg} / \mathrm{L}$ were required at the $\mathrm{Zn}^{2+}$ concentration of $0.2 \mathrm{mg} / \mathrm{L}$ and $0.5 \mathrm{mg} / \mathrm{L}$, respectively. Nevertheless, only a dosage of $2 \mathrm{mg} / \mathrm{L}$ at the $\mathrm{Zn}^{2+}$ concentration of $0.2 \mathrm{mg} / \mathrm{L}$ and a dosage of $1 \mathrm{mg} / \mathrm{L}$ at the $\mathrm{Zn}^{2+}$ concentration of $0.5 \mathrm{mg} / \mathrm{L}$ were needed to achieve similar corrosion inhibition for ST, exhibiting better corrosion inhibition for ST than that of SG and SC, which was possibly due to the more active functional groups available in the presence of ST. The corrosion inhibition mechanism of hydroxyl carboxylates is shown in Fig. 6. Chelation of iron oxides by hydroxyl and carboxyl groups linked to two adjacent carbon atoms is mainly responsible for the corrosion inhibition. The iron oxides here could be replaced by zinc and calcium salts, and a complex 'protective film' could be formed on the surface of the mild steel. Since a molecule of ST has two of these chelating groups but SG and SC only have one, ST should exhibit better corrosion inhibition than SG and SC. Furthermore, the molecular weight of hydroxyl carboxylates follows the order of SC > SG > ST, indicating that the amount of the chelating groups follows the opposite order at the same dosage of hydroxyl carboxylates by weight. The relationship between the corrosion inhibition by hydroxyl carboxylates and the amount of chelating groups was in good agreement with the experimental results.

\subsection{Corrosion inhibition study on RCWS}

\subsubsection{Corrosion inhibition by a hydroxyl carboxylate alone}

The corrosion inhibition of the three hydroxyl carboxylates separately was studied under the condition of simulated recirculating cooling water at the $\mathrm{Ca}^{2+}$ concentration of $1500 \mathrm{mg} / \mathrm{L}$, and the experiments were performed in the absence of phosphate. As shown in Fig. 7, a corrosion rate of below $0.075 \mathrm{~mm} /$ year, which met the requirements of international standard regulations for recirculating cooling water treatment (European Committee for Standardization, 2006), was achieved at the SG dosage of $80 \mathrm{mg} / \mathrm{L}$, SC dosage of $200 \mathrm{mg} / \mathrm{L}$ and ST dosage of $40 \mathrm{mg} / \mathrm{L}$, respectively, which followed the same order of corrosion inhibition for the three hydroxyl carboxylates as observed under the conditions of PRWS in Section 1.4. Much higher amounts of hydroxyl carboxylates were required for satisfactory corrosion inhibition, since no corrosion inhibition additives were supplemented in this experiment. Thus, a study on the corrosion inhibition of the combination of hydroxyl carboxylates and $\mathrm{Zn}^{2+}$ was necessary to lower the dosage of hydroxyl carboxylates.
2.2.2. Combination of hydroxyl carboxylates and zinc sulfate As reported in previous studies, the combination of SG and $\mathrm{Zn}^{2+}$ showed good corrosion inhibition for various metals (Manjula, 2009). Fig. 8a shows that the corrosion rate declined when the dosage of SG and $\mathrm{Zn}^{2+}$ was increased, and satisfactory corrosion inhibition was obtained at an SG dosage of $10 \mathrm{mg} / \mathrm{L}$ and $\mathrm{Zn}^{2+}$ dosage of $1.5 \mathrm{mg} / \mathrm{L}$, proving the synergetic effect of SG and $\mathrm{Zn}^{2+}$ on the corrosion inhibition of mild steel. However, the same corrosion inhibition could not be achieved at a $\mathrm{Zn}^{2+}$ dosage of $0.5 \mathrm{mg} / \mathrm{L}$ even if $50 \mathrm{mg} / \mathrm{L}$ of SG was added, suggesting that it was important to maintain a sufficient concentration of $\mathrm{Zn}^{2+}$ for efficient corrosion inhibition. The synergetic corrosion inhibition of SC or ST, however, was not investigated in detail in previous studies. Fig. $8 \mathrm{~b}$ shows that no obvious enhancement of corrosion inhibition was observed at a $\mathrm{Zn}^{2+}$ dosage of $0.5 \mathrm{mg} / \mathrm{L}$ as the SC dosage increased from 10 to $50 \mathrm{mg} / \mathrm{L}$, suggesting that $\mathrm{Zn}^{2+}$ barely had a synergetic effect with SC at low concentrations. As the $\mathrm{Zn}^{2+}$ dosage increased to $1.0 \mathrm{mg} / \mathrm{L}$, the corrosion rate dropped significantly, but the required corrosion inhibition could not be obtained until the SC dosage reached $30 \mathrm{mg} / \mathrm{L}$. Moreover, the corrosion could be well controlled at the dosages of SC and $\mathrm{Zn}^{2+}$ of 10 and $2.0 \mathrm{mg} / \mathrm{L}$ respectively. Fig. $8 \mathrm{c}$ shows that ST had an excellent synergistic effect on corrosion inhibition with $\mathrm{Zn}^{2+}$, and the combination of ST and $\mathrm{Zn}^{2+}$ could efficiently slow down the corrosion to meet the standard requirements at an ST

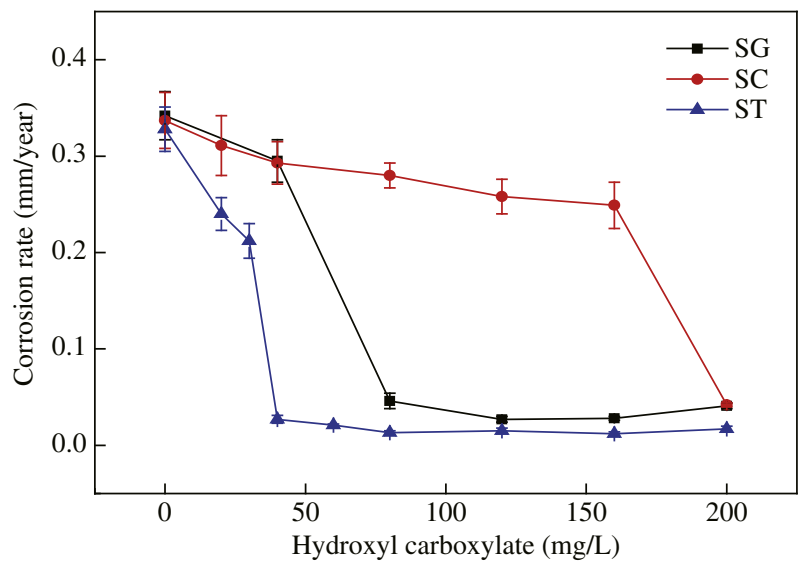

Fig. 7 - The corrosion inhibition of hydroxyl carboxylates alone in the simulative cooling water in the absence of phosphate. Experimental condition: $\mathrm{RS}=75 \mathrm{r} / \mathrm{min}$; temperature $=45^{\circ} \mathrm{C}$. SG: sodium gluconate, SC: sodium citrate, ST: sodium tartrate 

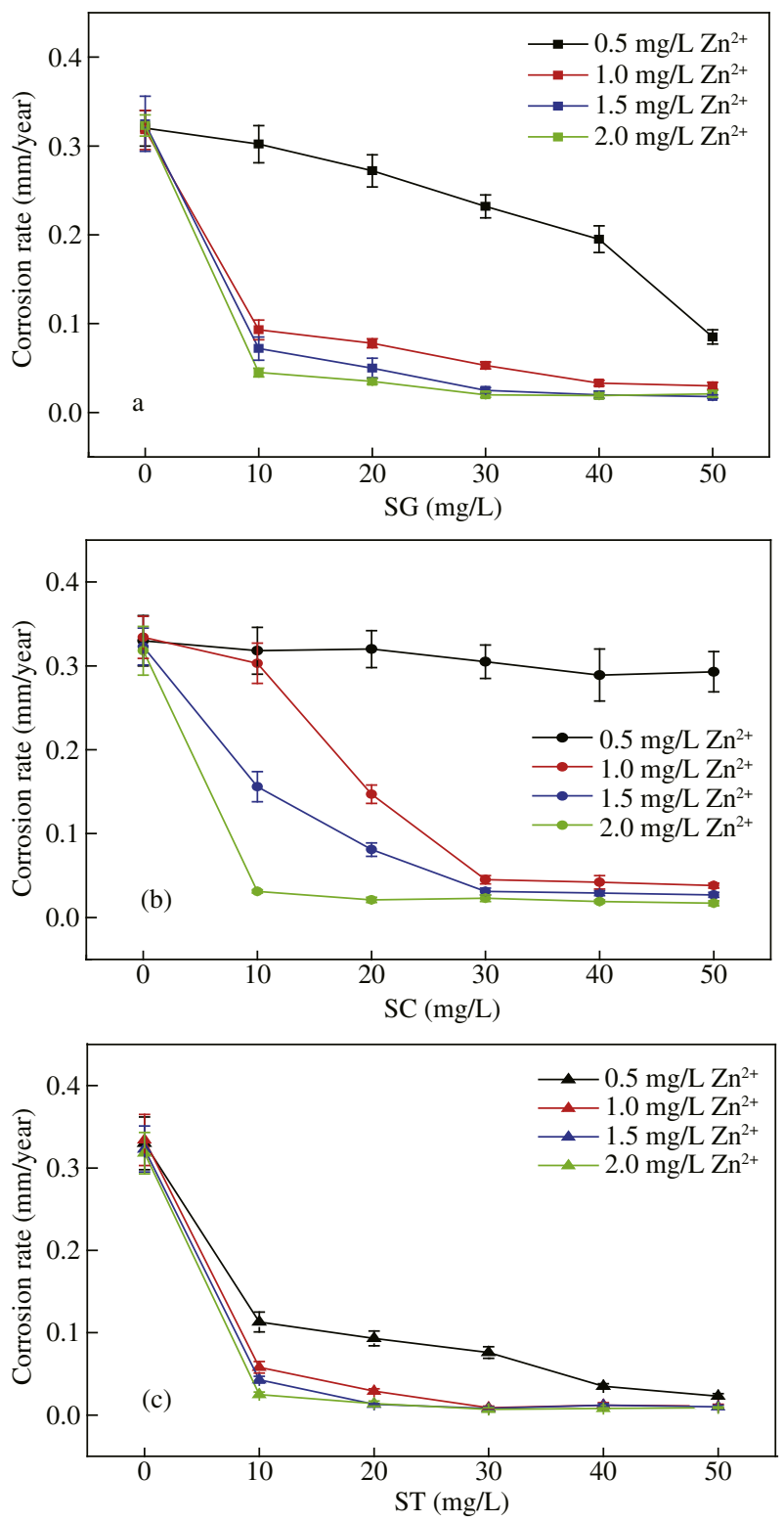

Fig. 8 - The synergetic corrosion inhibition of hydroxyl carboxylates and $\mathrm{Zn}^{2+}$ in the simulative cooling water in the absence of phosphate. (a) SG (sodium gluconate); (b) SC (sodium citrate); (c) ST (sodium tartrrate). Experimental condition: $\mathrm{RS}=75 \mathrm{r} / \mathrm{min}$; temperature $=45^{\circ} \mathrm{C}$.

dosage of $30 \mathrm{mg} / \mathrm{L}$ and $\mathrm{Zn}^{2+}$ dosage of $0.5 \mathrm{mg} / \mathrm{L}$. As the $\mathrm{Zn}^{2+}$ dosage increased to $1.0 \mathrm{mg} / \mathrm{L}$, corrosion inhibition could also be achieved at a ST dosage of $10 \mathrm{mg} / \mathrm{L}$, indicating that ST had much better corrosion inhibition capability than SG and SC when combined with $\mathrm{Zn}^{2+}$.

\subsubsection{Development of non-phosphorus formula}

Three non-phosphorus formulas for recirculating cooling water treatment were developed using hydroxyl carboxylates as the main corrosion inhibitors and $\mathrm{Zn}^{2+}$ as a corrosion inhibitive additive based on the previous experimental results. PESA as anti-scalant and LN-104B as dispersant were supplemented into the formula, and their dosages were $6 \mathrm{mg} / \mathrm{L}$ and

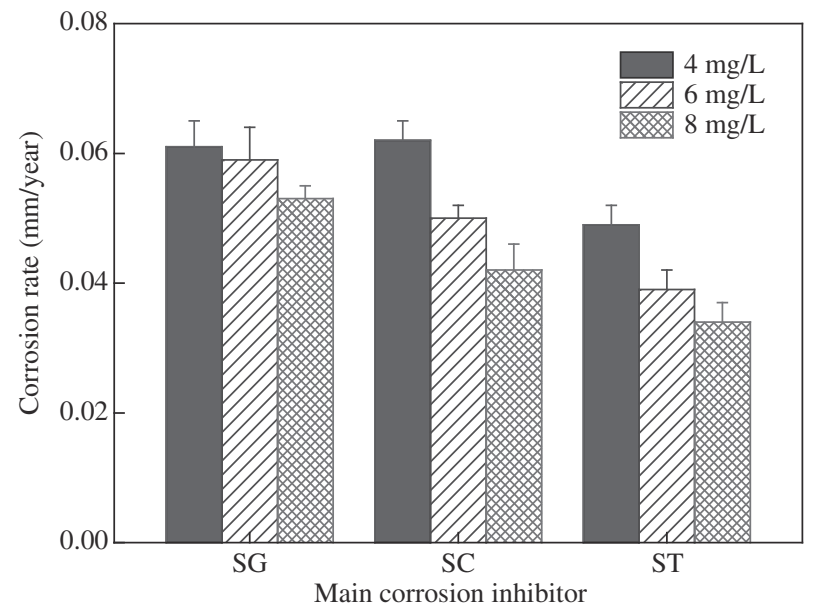

Fig. 9 - The corrosion inhibition of the non-phosphorous programs dominated by hydroxyl carboxylates in the simulated cooling water. Experimental condition: RS = 75 r/min; temperature $=45^{\circ} \mathrm{C}$. SG: sodium gluconate, SC: sodium citrate, ST: sodium tartrate.

$10 \mathrm{mg} / \mathrm{L}$, respectively. Since PESA was also known as a corrosion inhibitor and proved to have a significant synergetic effect with $\mathrm{Zn}^{2+}$ on inhibiting the corrosion of mild steel in previous studies (Zhang et al., 2015), an experiment at a $\mathrm{Zn}^{2+}$ dosage of $2.0 \mathrm{mg} / \mathrm{L}$ was carried out at even lower dosages of hydroxyl carboxylates to assess the corrosion inhibition of the formulas. As shown in Fig. 9, the corrosion rates were restricted to below $0.075 \mathrm{~mm} /$ year at a dosage range of hydroxyl carboxylates of $4-8 \mathrm{mg} / \mathrm{L}$, suggesting that the amount of hydroxyl carboxylates dosed could be substantially reduced by combining with PESA, in contrast to the experimental results shown in Section 2.2. Moreover, the formulas including ST had higher corrosion inhibitive performance than the formulas having SG or SC, which agreed the experimental results in the absence of PESA. As a result, the best non-phosphorus formula was determined and labeled as RWNP-1.

\subsection{Pilot-scale experiment and integrated corrosion inhibition process design}

\subsubsection{Pilot-scale experiment}

A pilot-scale experiment was carried out to test the performance of RWNP-1 under a highly concentrated recirculating cooling water condition (more than 5.0 cycles of concentration) and the results are shown in Table 2. The corrosion rate and adhesion rate of the test tubes were $0.034 \mathrm{~mm} /$ year and $3.52 \mathrm{mg} /\left(\mathrm{cm}^{2} \cdot\right.$ month$)$, respectively; both met the requirements of recirculating cooling water treatment (the adhesion rate was required to be below $15 \mathrm{mg} /\left(\mathrm{cm}^{2} \cdot \mathrm{month}\right)$ (Manufacturing and Developing Department of SINOPEC, 1993). For comparison, results from previous studies (Sun et al., 2014; Tao et al., 2011; Zeng et al., 2006; Wu et al., 2014; Qin and Li, 2013) on the application of other non-phosphorus formulas operated in either pilot-scale or full-scale RCWSs are presented in Table 2. As shown in Table 2, all of the corrosion rates were less than $0.075 \mathrm{~mm} /$ year, and all adhesion rates were less than $15 \mathrm{mg} /\left(\mathrm{cm}^{2} \cdot \mathrm{month}\right)$. This means that satisfactory corrosion and 


\begin{tabular}{|c|c|c|c|c|c|c|c|c|}
\hline \multirow[t]{2}{*}{ No. } & \multirow[t]{2}{*}{$\begin{array}{l}\text { Water treatment } \\
\text { chemical program }\end{array}$} & \multirow[t]{2}{*}{ Scale } & \multirow[t]{2}{*}{$\begin{array}{c}\mathrm{Ca}^{2+} \\
(\mathrm{mg} / \mathrm{L})\end{array}$} & \multirow[t]{2}{*}{$\begin{array}{c}\text { Cycles of } \\
\text { concentration }\end{array}$} & \multicolumn{2}{|c|}{$\begin{array}{l}\text { Corrosion rate } \\
(\mathrm{mm} / \mathrm{y})\end{array}$} & \multirow[t]{2}{*}{$\begin{array}{l}\text { Adhesion rate } \\
\left(\mathrm{mg} /\left(\mathrm{cm}^{2} \cdot \mathrm{month}\right)\right)\end{array}$} & \multirow[t]{2}{*}{ References } \\
\hline & & & & & Test tube & Coupon & & \\
\hline 1 & RWNP-1 & Pilot & $\approx 1600$ & $>6.0$ & 0.034 & 0.021 & 3.52 & / \\
\hline 2 & AE4135 & Pilot & $<1100$ & $4.0-5.0$ & 0.011 & 0.010 & 2.52 & Touir et al., 2014 \\
\hline 3 & ANONYMITY & Pilot & $<700$ & $4.0-5.0$ & 0.035 & 0.005 & 2.68 & Wang et al., 2015 \\
\hline 4 & ZH800WS & Full & $<250$ & $<2.5$ & 0.047 & 0.032 & 11.22 & Wu et al., 2014 \\
\hline 5 & HB80BZN & Full & $<520$ & $<4.0$ & $<0.07$ & / & I & Yi et al., 2011 \\
\hline 6 & YSW109 & Full & $\approx 1100$ & $\approx 7.0$ & 0.042 & I & 10.30 & Zeng et al., 2006 \\
\hline
\end{tabular}

scale inhibition can also be achieved in whole-system studies. However, comparing the $\mathrm{Ca}^{2+}$ concentrations in Table 2, the $\mathrm{Ca}^{2+}$ concentrations of RCWSs from the literature were all lower than $1100 \mathrm{mg} / \mathrm{L}$, clearly demonstrating that RWNP-1 was more efficient than other formulas in terms of corrosion inhibition, since it can be effectively applied at the $\mathrm{Ca}^{2+}$ concentration of around $1600 \mathrm{mg} / \mathrm{L}$. In particular, the pilot-scale RCWS in the present study used reclaimed water, which was more corrosive than the fresh water used for make-up water in the previous studies. ST therefore was proposed as an alternative to non-phosphorus corrosion inhibitors like PESA and polyaspartic acid.

\subsubsection{Integrated corrosion inhibition process}

Based on the experimental results, an integrated corrosion inhibition process was developed. The process included corrosion inhibition in both PRWS and downstream RCWSs, with the reclaimed water used as make-up, which is illustrated in Table 3.

When the $\mathrm{PO}_{4}^{3-}$ concentration in the reclaimed water was more than $1.7 \mathrm{mg} / \mathrm{L}$, satisfactory corrosion inhibition in the PRWS could be achieved by dosing with a small quantity of $\mathrm{Zn}^{2+}(>0.5 \mathrm{mg} / \mathrm{L})$ as a synergist. There was no need to add extra corrosion inhibitors in the downstream RCWS, since sufficient $\mathrm{PO}_{4}^{3-}$ and $\mathrm{Zn}^{2+}$ would be present in the RCWS, as the reclaimed water was concentrated more than 5 times. The corrosion inhibition requirement of the RCWS can be met by the combination of $\mathrm{PO}_{4}^{3-}$ and $\mathrm{Zn}^{2+}$, based on previous studies (Wang et al., 2015).

However, when the $\mathrm{PO}_{4}^{3-}$ concentration in the reclaimed water was below $1.7 \mathrm{mg} / \mathrm{L}$, the addition of corrosion inhibitors in the PRWS was required. A non-phosphorus corrosion inhibitor, ST, then was recommended to successfully improve the corrosion inhibition with dosage of above $1.0 \mathrm{mg} / \mathrm{L}$, and higher dosage of above $2.0 \mathrm{mg} / \mathrm{L}$ would be applied if scarcely any $\mathrm{PO}_{4}^{3-}$ was present in the reclaimed water. Likewise, no extra corrosion inhibitors were required in the downstream RCWSs to satisfy the corrosion inhibition requirements.

\section{Conclusions}

Aiming to mitigate the corrosion in PRWS, a process was developed by utilizing the phosphate in the reclaimed water as a corrosion inhibitor. The combination of $\mathrm{PO}_{4}^{3-}$ and $\mathrm{Zn}^{2+}$ led to satisfactory corrosion inhibition in the PRWS when the $\mathrm{PO}_{4}^{3-}$ and $\mathrm{Zn}^{2+}$ concentrations were greater than $1.7 \mathrm{mg} / \mathrm{L}$ and $0.5 \mathrm{mg} / \mathrm{L}$ respectively. However, when the $\mathrm{PO}_{4}^{3-}$ concentration in the reclaimed water was below $1.7 \mathrm{mg} / \mathrm{L}$, the same corrosion inhibition was achieved with the aid of hydroxyl carboxylate-based non-phosphorus corrosion inhibitors at dosages above $1.0 \mathrm{mg} / \mathrm{L}$. So, to sum up, when the reclaimed water was used for the RCWS as the make-up, the RCWS could be operated well at high cycles of concentration condition and the corrosion inhibition requirement was met, with no extra corrosion inhibitors being required. The integrated process prevented the PRWS and the downstream RCWS from corrosion simultaneously. The proposed process could also reduce the cost of the RCWS and the environmental risk of excess phosphorus emission.

\section{Acknowledgments}

This work was supported by the Key Laboratory of Drinking Water Science and Technology, Chinese Academy of Sciences (No. 15Z01KLDWST) and the National Natural Science Foundation of China (Nos. 51378491 and 51578533).

Table 3 - The integrated process conditions for dosing inhibitors in pipeline of reclaimed water supplies (PRWS) and downstream RCWS.

\begin{tabular}{|c|c|c|c|c|c|c|c|}
\hline \multirow[t]{2}{*}{ Case } & \multirow{2}{*}{$\begin{array}{c}\left(\mathrm{PO}_{4}^{3-}\right)_{\text {initial }} \\
(\mathrm{mg} / \mathrm{L})\end{array}$} & \multicolumn{3}{|c|}{ PRWS } & \multicolumn{3}{|c|}{ RCWS } \\
\hline & & $\begin{array}{l}\mathrm{Zn}^{2+} \\
(\mathrm{mg} / \mathrm{L})\end{array}$ & $\begin{array}{c}\mathrm{PO}_{4}^{3-} \\
(\mathrm{mg} / \mathrm{L})\end{array}$ & $\begin{array}{c}\mathrm{ST} \\
(\mathrm{mg} / \mathrm{L})\end{array}$ & $\begin{array}{c}\mathrm{PO}_{4}^{3-} \\
(\mathrm{mg} / \mathrm{L})\end{array}$ & $\begin{array}{c}\mathrm{Zn}^{2+} \\
(\mathrm{mg} / \mathrm{L})\end{array}$ & $\begin{array}{c}\mathrm{ST} \\
(\mathrm{mg} / \mathrm{L})\end{array}$ \\
\hline 1 & $>1.7$ & $>0.5$ & / & I & $>7.0$ & $>2.0$ & I \\
\hline 2 & $<1.7$ & $>0.5$ & $>1.7$ & I & $>7.0$ & $>2.0$ & I \\
\hline 3 & $<1.7$ & $>0.5$ & $<1.7$ & $>1.0$ & $>7.0$ & $>2.0$ & $>5.0$ \\
\hline 4 & $\approx 0$ & $>0.5$ & $\approx 0$ & $>2.0$ & $\approx 0$ & $>2.0$ & $>10.0$ \\
\hline
\end{tabular}




\section{R E F E R E N C E S}

Belakhmima, R.A., Dkhireche, N., Touir, R., Touhami, M.E., 2015. Development of multi-component SG with CTAB as corrosion, scale, and microorganism inhibitor for cooling water systems. Mater. Chem. Phys. 152, 85-94.

Buchheit, R.G., 2005. Corrosion resistant coatings and paints. Handbook of Environmental Degradation of Materials. Elsevier Inc, London, pp. 367-385.

Chien, S.H., Hsieh, M.K., Li, H., Monnell, J., Dzombak, D., Vidic, R., 2012. Pilot-scale cooling tower to evaluate corrosion, scaling, and biofouling control strategies for cooling system makeup water. Rev. Sci. Instrum. 83 (2), 1-10.

China Association for Chemical Standardization, 2000. Determination of Corrosion Inhibition Performance of Water Treatment Agents - Rotation Specimen Method (GB/T 18175-2000). Chinese Standard Press, Beijing, China.

China E.P.A., 2002. Analysis Method of Water and Wastewater (4th Edition). China Environmental Science Press, Beijing, China.

China Ministry of Housing and Urban-Rural Development, 2005. The Reuse of Urban Recycling Water - Water Quality Standard for Industrial Uses (GB/T 19923-2005). Chinese Standard Press, Beijing, China.

Choudhury, M.R., Hsieh, M.K., Vidic, R.D., Dzombak, D.A., 2012. Corrosion management in power plant cooling systems using tertiary-treated municipal wastewater as makeup water. Corros. Sci. 61, 231-241.

Edwards, M., 2004. Controlling corrosion in drinking water distribution systems: a grand challenge for the 21st century. Water Sci. Technol. 49 (2), 1-8.

Ellenberger, J.P., 2014. Selection and use of pipeline materials. Piping and Pipeline Calculations Manual 2nd edition. Elsevier Inc, London, pp. 19-32.

European Committee for Standardization, 2006. Corrosion of Metals and Alloys - Corrosion and Fouling in Industrial Cooling Water Systems (ISO 16784-2006) (Switzerland).

Frayne, C., 1999. Cooling Water Treatment - Principles and Practice. Chemical Publishing Company Inc., New York.

Kim, G.E., Lee, H.D., Kwak, P.J., Kang, S.W., 2012. Influence factor and corrosion characteristics in pipe system for water reclamation. IWA World Water Congress \& Exhibition. Busan, Korea. September 16-21.

Manjula, P., 2009. Corrosion inhibition by sodium gluconate- $\mathrm{Zn}^{2+}$-DTPMP system. E. J. Chem. 6 (3), 887-897.

Manufacturing and Developing Department of SINOPEC, 1993. Analysis and Testing Method of Cooling Water. Information Center of Anqing Petrochemical Corporation, Anqing, China.

Müller, B., 2004. Citric acid as corrosion inhibitor for aluminium pigment. Corros. Sci. 46 (1), 159-167.

Qin, H.M., Li, H.S., 2013. Development and industrial application of non-phosphorus corrosion and scale inhibitor YSW109. Mod. Chem. Ind. 33 (1), 90-91.
Razi, S.M.S., 1989. Corrosion Inhibition by Zn-phosphate Systems in Neutral Solutions PhD thesis UMIST, Manchester, UK.

Renuka, R., Ramamurthy, S., Muralidharan, K., 1998. Effect of citrate, tartrate and gluconate ions on the behaviour of zinc in $3 \mathrm{M} \mathrm{NaOH}$. J. Power Sources 76, 197-209.

Romer, A., Passaro, P., 2007. Risk management of pipeline corrosion in the water and wastewater industries. International Conference on Pipeline Engineering and Construction. Boston, USA. July 8-11.

Safari, I., Walker, M.E., Hsieh, M.K., Dzombak, D.A., Liu, W.S., Vidic, R.D., Miller, D.C., Abbasian, J., 2013. Utilization of municipal wastewater for cooling in thermo-electric power plants. Fuel 111, 103-113.

Sastri, V.S., 2011. Green Corrosion Inhibitors: Theory and Practice. John Wiley \& Sons Inc., Hoboken.

Shao, H.B., Wang, J.M., Zhang, Z., Zhang, J.Q., Cao, C.N., 2002. The cooperative effect of calcium ions and tartrate ions on the corrosion inhibition of pure aluminum in an alkaline solution. Mater. Chem. Phys. 77 (2), 305-309.

Sun, X.D., Chen, A.Q., Xu, F., 2014. Research and application of non-phosphorus scale-corrosion inhibitor for circulating water system. Contemp. Chem. Ind. 43 (7), 1290-1292.

Tao, W.R., Chen, B.W., Ji, S.Y., Jiang, Y.Z., 2011. Research and development on non-phosphorus circulating cooling water treatment agents. Ind. Water Treat. 31 (8), 72-73.

Touir, R., Cenoui, M., Bakri, M.E., Touhami, M.E., 2008. Sodium gluconate as corrosion and scale inhibitor of ordinary steel in simulated cooling water. Corros. Sci. 50, 1530-1537.

Touir, R., Dkhireche, N., Touhami, M.E., Bakri, M.E., Rochdi, A.H., Belakhmima, R.A., 2014. Study of the mechanism action of sodium gluconate used for the protection of scale and corrosion in cooling water system. J. Saudi Chem. Soc. 18, 873-881.

Wang, D., Wang, J., Luan, Z.K., Wu, Y., Li, H.S., 2015. Comprehensive utilization of phosphate in a highly concentrated recirculating cooling water system using secondary-treated municipal wastewater as makeup. Desalin. Water Treat. http://dx.doi.org/10.1080/19443994.2015.1037354.

Wu, D.L., Liu, X., Liu, S.Q., 2014. Application of green and phosphorus-free corrosion and scale inhibitors to circulating cooling water systems in power plants. Ind. Water Treat. 34 (4), 86-89.

Yi, L.L., Jiao, W.T., Chen, X.N., Chen, W.P., 2011. An overview of reclaimed water reuse in China. J. Environ. Sci. 23 (10), 1585-1593.

Zeng, F.L., Wu, Y.F., Du, L.L., Jin, J.F., 2006. Application of non-phosphorus scale and corrosion inhibitor ZH800WS. Ind. Water Treat. 26 (7), 77-80.

Zhang, B.R., He, C.J., Wang, C., Sun, P.D., Li, F.T., Lin, Y., 2015. Synergistic corrosion inhibition of environment-friendly inhibitors on the corrosion of carbon steel in soft water. Corros. Sci. 94, 6-20. 